\title{
Pentoxyfilline Effect on Reduction of Proteinuria to PATIENTS With Diabet Type-2
}

\author{
Ibrahim Rudhani ${ }^{1}$, Naim Morina ${ }^{2}$ and Ahmet Avdullahu ${ }^{3}$ \\ ${ }^{1}$ Internal Medicine Specialist-Nephrologist, Kosovo \\ ${ }^{2}$ Resident of Internal Medicine Clinic of Nephrology, Hemodialysis UCCK Kosovo Hospital Circle, Kosovo \\ ${ }^{3}$ Specialist of Internal Medicine Clinic of Nephrology and Hemodialysis UCCK Kosovo Hospital Circle, Kosovo
}

Received: February 28, 2018; Published: March 21, 2018

*Corresponding author: Naim Morina, Resident of Internal Medicine Clinic of Nephrology and Hemodialysis UCCK Kosovo Hospital Circle n.n. 10000 Pristina, Kosovo, Tel: +381385006003565; GSM: +37744320307; Email: naim_morina@hotmail.com

\begin{abstract}
The purpose of this study was to evaluate the effect of Pentoxifylline on the reduction of proteinuria of type 2 diabetes mellitus patients who were being treated with ACE and ARB. The study was prospective and was achieved for six months at the Nephrology Clinic, UCCK, between January and June 2016. The study included 162 patients with type 2 diabetes, diabetic patients with proteinuria above $500 \mathrm{mg} / 24 \mathrm{~h}$ despite being treated with ACE Inhibitors and ARB. The patient group is treated with Pentoxiphylline (oral) $400 \mathrm{mg} 3$ times a day. Proteinuria for 24 hours was evaluated at the beginning of the study, then in the first quarter and after six months treatment with Pentoxiphylline. In the other group 80 healthy individuals treated with Placebo. Both groups have adapted the study to eliminating patients with comorbidities. To the all patients and subjects of the control group were taken anamnesis, also it was made objective examination, biochemical laboratory tests and hematologic tests of Proteinuria for 24 hours. The standard deviation and T-test are used for data analysis. During the six-month study of these patients treated with Pentoxiphyllin $400 \mathrm{mg}$ (oral) proteinuria was very early. In the first three months, there was a decrease in proteinuria or decreased protein loss through urine. The average age was 59.13, of which 86 males and 76 females were involved in the research.
\end{abstract}

Keywords: Diabetes Mellitus; Nephropathia Diabetica; Pentoxifylline; Chronic Kidney Failure

\section{Introduction}

Diabetes mellitus is a group of common metabolic disorders characterized by increased glycemic blood levels. With the increasing prevalence of diabetes worldwide, it still remains one of the most common causes of morbidity and mortality in the world. Although the prevalence of both types of diabetes is increasing worldwide, it has been expected that type 2 diabetes mellitus (T2DM) will grow more in the future due to obesity and unpleasant physical activity. Late (secondary) complications to diabetics are: retinopathy, neuropathy and nephropathy. Diabetic nephropathy is considered the most common cause of kidney failure (ESRD) [1]. Recently, treatment options have been increased in decreasing disease progression by improving kidney function. Approximately 35 to $50 \%$ of all ESRD-dependent (kidney disorder) need active treatment (replacement of kidney function), including Hemodialysis, peritoneal dialysis or abdominal transplant are complications of diabetes type 2 diabetic nephropathy. Since long-range dialysis is costly and causes disabilities to work for the patient, the preventive not to advance in the stages of kidney failure or ESRD seems to be the most logical way to reduce patients' costs and suffering and also postpone active dialysis treatment or kidney transplantation [2].

In major studies done in a large number of patients with diabetes, proteinuria is the worst being a risk factor for advancement at the last stage of renal disease [3]. Increased risk for kidney damage justifies the need to reduce Proteinuria in these patients [4]. Currently ACEs and ARBs are used to reduce Proteinuria [5]. Therefore, maximum renal protection can be reached by decreasing proteinuria [6]. In almost all cases, more than one treatment is needed to achieve this goal [7]. Recent research has shown that pentoxifylline (PTX) has the ability to reduce proteinuria in diabetic patients with normal renal function [8]. Pentoxifylline is a methylxanthine which regulates blood flow and a non-selective phosphodiesterase inhibitor which reduces inflammatory factors including TNF-, IL-1 and IL-6 and plays an important role in the pathogenesis of interstitial renal fibrosis and advancing diabetic nephropathy [9-11]. Existing experimental human and animal data show that there is a strong scientific basis for the use of pentoxifylline as an antiproteinuric medicament $[12,13]$. 
For this reason, it appears that pentoxifylline can maintain kidney function with further reduction of proteinuria and then reduces cardiovascular complications. The first line therapy in preventing or decreasing the loss of protein in the urine is ACE or ARB which usually is achieved a satisfactory modification but in other cases the use of Pentoxifylline, which is satisfying, decreases the proteinuria for 24 hours and also other complications resulting from protein loss [14]. The cardiovascular mortality rate in these patients is 10-20 times higher than the total population [15]. Arterial hypertension occurs in $60-90 \%$ of patients with renal insufficiency, prior to hemodialysis [16]. Congestive heart failure is a cause of mortality at around $20-30 \%$ of cases in these patients (2.4).

\section{a) Study Aim}

The purpose of this study was to evaluate the efficacy of pentoxifylline in reducing proteinuria in patients with type 2 diabetes mellitus although they were being treated with ACE and ARB.

\section{Research Methodology}

The study was conducted at the Hemodialysis Nephrology Clinic, University Clinical Center of Kosovo, from January 1, 2016 to June 30,2016 . The study was prospective including 162 patients with type 2 diabetes, diabetic patients with proteinuria above $500 \mathrm{mg} / 24 \mathrm{~h}$, despite being treated with ACE inhibitors and ARB. The patient group is treated with Pentoxifylline $400 \mathrm{mg} 3$ times a day. Proteinuria for 24 hours was evaluated at the beginning of the study, then in the first quarter and after six months. The other group included 80 healthy subjects treated with Placebo. Both groups have adapted to the study, patients with comorbidities have been eliminated. To the all patients and subjects of the control group were taken anamnesis, and objective examination was made, biochemical laboratory tests and hematologic tests of Proteinuria for 24 hours. The statistical methods of the application are descriptive analysis (standard deviation averages), and $\mathrm{T}$ test.

\section{Results}

Out of 162 patients in the study treated for six months with Pentoxiphyllin $400 \mathrm{mg}$ (oral), three times a day by 1 tablet, proteinuria was very early in the first three months that there was a decrease in the values of Proteinuria or decrease of protein loss for urine. The average age of patients was 59.13 (Figure 1). Out of 162 examined and treated patients, there were 86 males and 76 females (Figure2). At the beginning of the treatment, the measurable proteinuria values were $2.64 \mathrm{~g}$ per 24 hours at a maximum of $5.7 \mathrm{~g} / \mathrm{l}$. 24 hours, minimum $0.9 \mathrm{~g} / \mathrm{l}$ for 24 hours. After three months of treatment with tab. Pentoxifylline $400 \mathrm{mg}$, a tablet three times a day, the average proteinuria value is $1.50 \mathrm{~g} / \mathrm{l}$, maximum is $4.1 \mathrm{~g} / \mathrm{l}$ and minimum $0.56 \mathrm{~g} / \mathrm{l}$ for 24 hours (Figure 3). After 6 months treatment with tab therapy Pentoxifylline $400 \mathrm{mg}$, a tablet three times a day, the average proteinuria value was $1.16 \mathrm{~g} / \mathrm{l}$, the maximum value is $2.2 \mathrm{~g} / \mathrm{l}$ and the minimal value is $0.22 \mathrm{~g} / \mathrm{l}$ (Figure 4). In the study group with placebo there were 37 females and 43 males, the average age of respondents in this study was 63.69 years. Initially, proteinuria was $125 \mathrm{mg}$, in the second quarter was $145 \mathrm{mg}$, and at six months it was also $125 \mathrm{mg}$, which is at the limit of normal proteinuria (Figure 5).

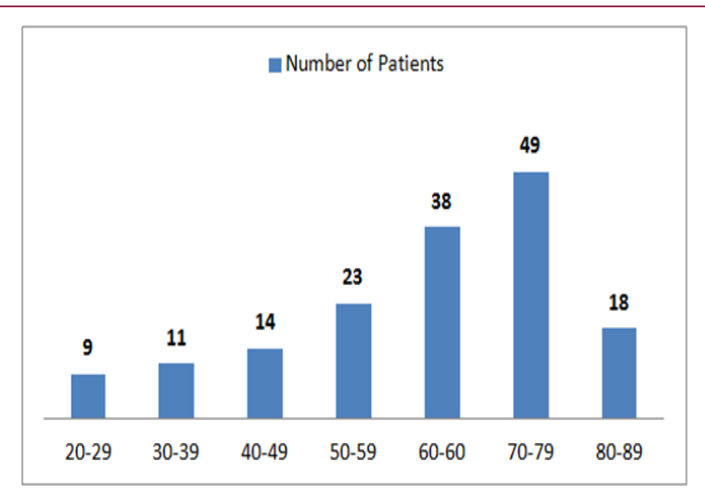

Figure 1: Graphic presentation of the most attacked age by diabetic Nephropathy.

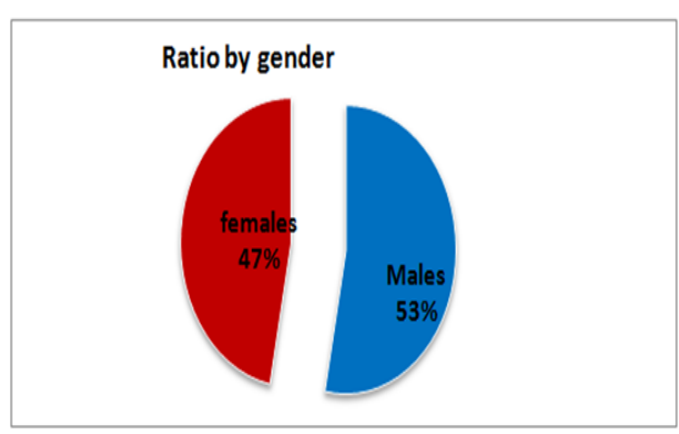

Figure 2: Representation of the Sex Ratio between Diabetic Nephropathy.

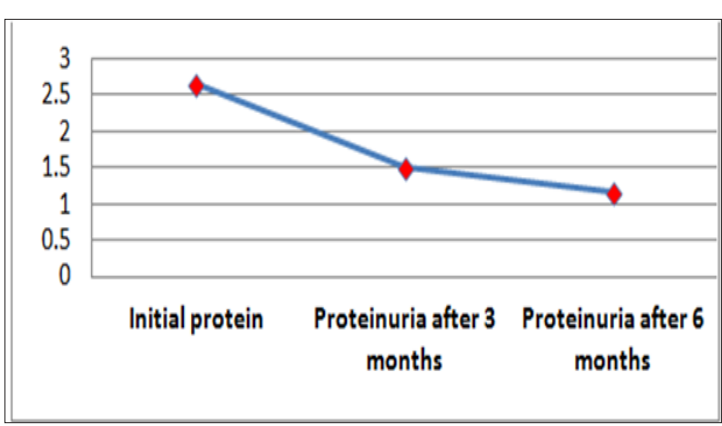

Figure 3: Graphic presentation of proteinuria after treatment with Pentoxifylline of diabetic nephropathy.

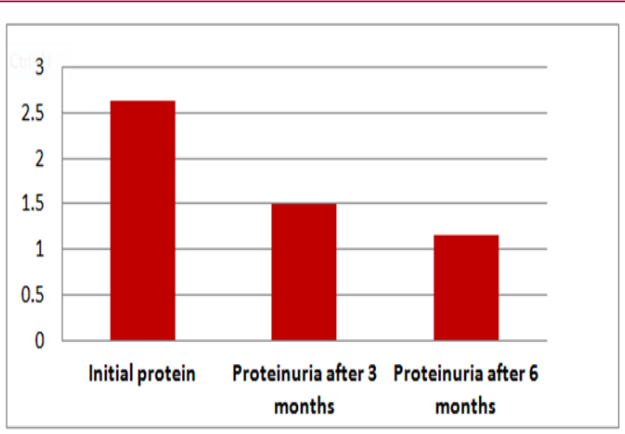

Figure 4: Graphic presentation of proteinuria after treatment with Pentoxifylline of diabetic nephropathy 


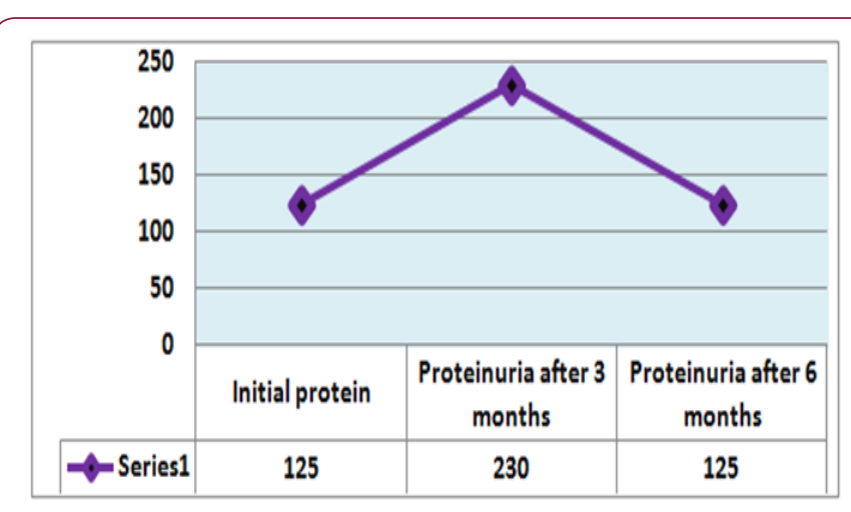

Figure 5: Presentation of proteinuria in control group (placebo) patients.

\section{Discussion of The Results}

From the examinations of our study we can see that men dominate more. Out of 162 patients treated, there were 86 males and 76 females while the average age of patients was 59.13. At the beginning of treatment with tab. Pentoxiphylline $400 \mathrm{mg}$, a tablet three times a day, since the beginning there is decrease in proteinuria value. After three months of treatment with tab. Pentoxifylline 400 $\mathrm{mg}$, a tablet three times a day at maximum starting point of $5.7 \mathrm{~g} /$ 1. 24 hours, there is a decrease after three months therapy and the value was reduced to $1.50 \mathrm{~g} / \mathrm{l}$. After 6 months of treatment with tab. Pentoxifylline $400 \mathrm{mg}$, a tablet three times a day the average proteinuria value was $1.16 \mathrm{~g} / \mathrm{l}$, the maximum value is $2.2 \mathrm{~g} / \mathrm{l}$ and the minimal value is $0.22 \mathrm{~g} / \mathrm{l}$. In the study group with placebo consisting of 80 subjects from whom 37 were female and 43 males, the average age of this subject was 63.69. At first, Proteinuria was $125 \mathrm{mg}$, the second quarter also $145 \mathrm{mg}$ and the half year was also $125 \mathrm{mg}$ which is at the limit of normal proteinuria [6].

In the framework of our study, we conducted the empirical analysis through the T-test, comparing the values of laboratory analysis in the group of patients treated with Pentoxifylline $400 \mathrm{mg}$ a tablet three times a day to the placebo patients group including three periods. From the results of the analysis we see that in three periods the proteinuria values in patients treated with therapy compared to the group of patients without therapy are significant because the value of $\mathrm{P}$ is 0,000 which means it is smaller than the allowed value $\mathrm{p}=0.05$. Comparison of leukocyte values between traumatic patients and control group also shows a significant difference since the $P$ value is $p=0.002$ which means that it is less than $\mathrm{p}=0.05$. Leukocyte lab analysis values are also presented in Table 1. Based on the results, a significant difference is observed in the comparison of erythrocytes in patients treated with therapy and control group as the value $\mathrm{p}=0.033$, which means that it is 0.05 . The values of the laboratory analysis of erythrocytes are also presented in Table1 and Figure 6. Unlike the leukocyte values and erythrocytes, hemoglobin values in patients treated with Pentoxiphyllin $400 \mathrm{mg}$ there aren't any significant difference with placebo patients. The values of the laboratory analysis of HGB are also presented in Table1 and Figure 6.

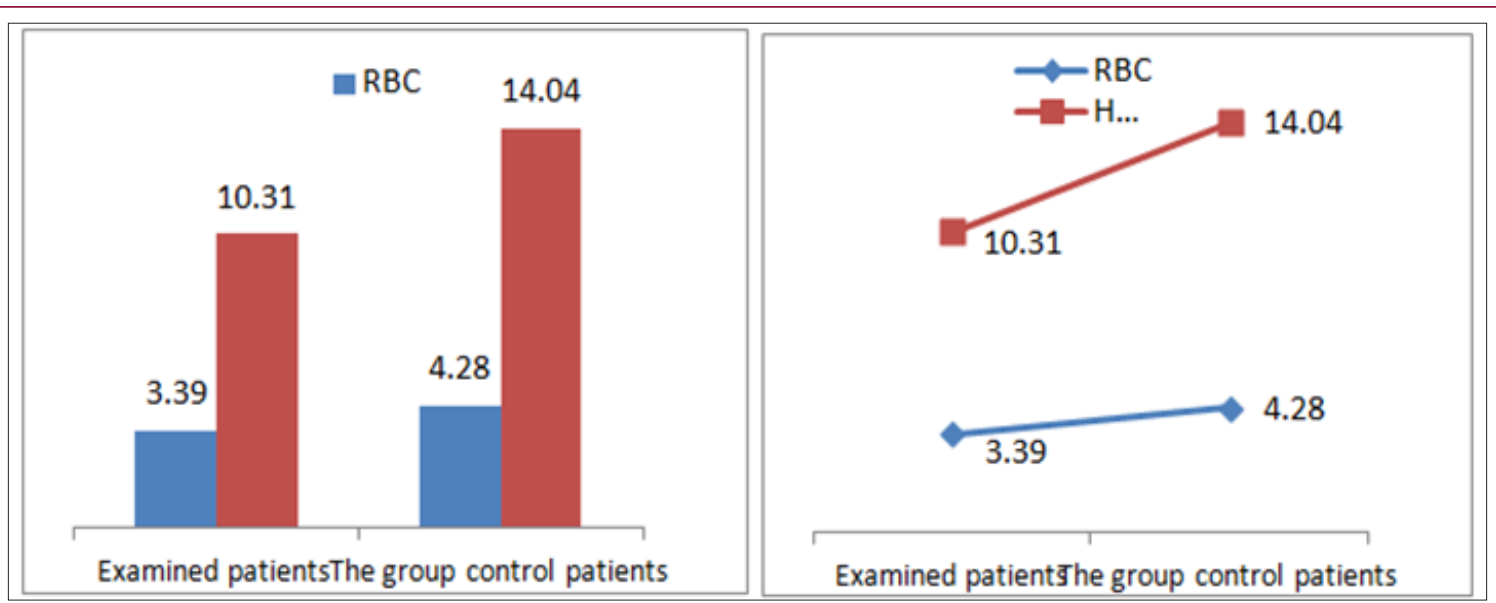

Figure 6: Graphic presentation of the values of erythrocytes and hemoglobin in patients with diabetic nephropathy and patients in the control group.

Table 1: Presentation of the analyzed values from examined patients and the patients of the control group.

\begin{tabular}{|c|c|c|}
\hline & Examined Patients & The Group Control PATIENTS \\
\hline WBC & 9.19 & 7.66 \\
\hline RBC & 3.39 & 4.28 \\
\hline HGB & 10.31 & 14.04 \\
\hline HCT & 28.57 & 39.42 \\
\hline UREA & 19.82 & 7.87 \\
\hline KREATININA & 310.89 & 81.06 \\
\hline ALT & 20.9 & 15.87 \\
\hline
\end{tabular}

\begin{tabular}{|c|c|c|}
\hline AST & 29.2 & 17.16 \\
\hline TOT.PROT & 51.53 & 70.85 \\
\hline ALBUMINA & 30.5 & 44.9 \\
\hline AC.URIC & 428.81 & 375 \\
\hline CHOLESTEROL & 5.63 & 4.04 \\
\hline TRIGLICERIDE & 1.83 & 1.57 \\
\hline
\end{tabular}

Also a significant difference based on the results is the values of Hematocrit, Creatinine, total of proteins, uric acid between treatments and control groups. This significance is confirmed by the value of P (HCT p-Values $=0.000$, Creatinine $p$-Value $=0.000$, 
Total Proteins $p$-value $=0.002$ and Uric Acid $p$-Value $=0.000$ ) where in four cases is less than 0.05 . These values are also presented graphically (Figures $7 \& 8$ ). While the values of laboratory analysis that did not have any significant statistical difference between patients treated with Pentoxiphyllin $400 \mathrm{mg}$ and placebo patients were: transaminase values (ALT, P-Value $=0.382$ ), AST values
(AST, P-Value $=0.483$ ), albumin values (albumin, P-Value $=0.603$ ), cholesterol values (Cholesterol, P-Value $=0.063$ ) and triglyceride values (Triglycerides, P-Value $=0.062$ ). In all cases we see that the values of $\mathrm{P}$ are greater than the allowed values 0.05 . These values are also presented graphically (Figure 9).

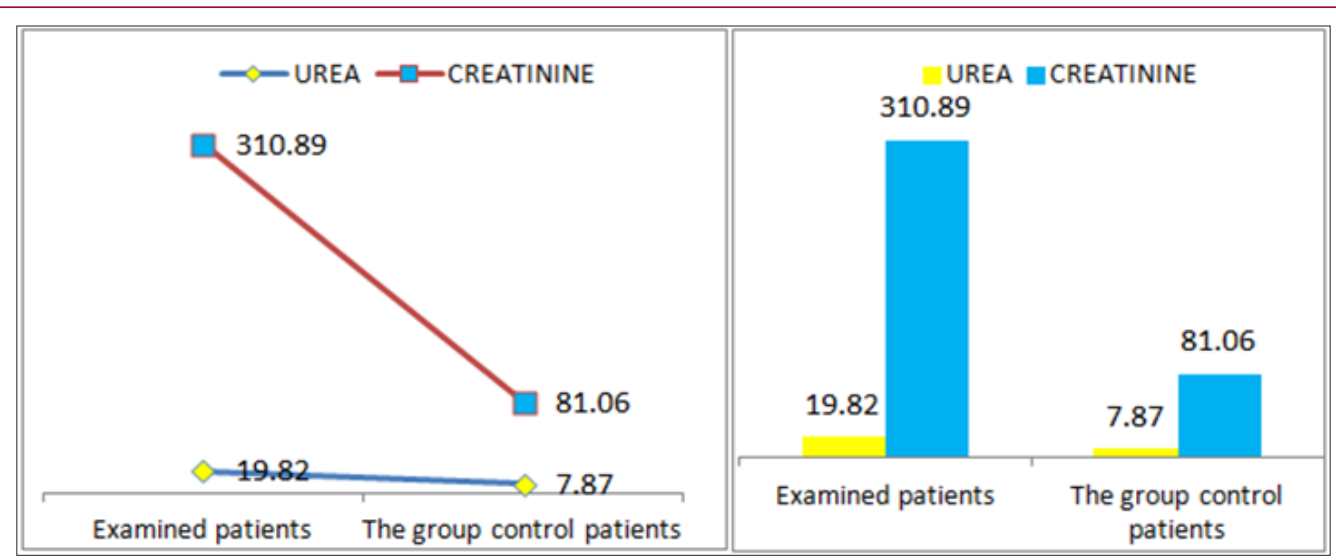

Figure 7: Graphic presentations of urine and Creatinine values in patients with diabetic nephropathy and patients in the control group.
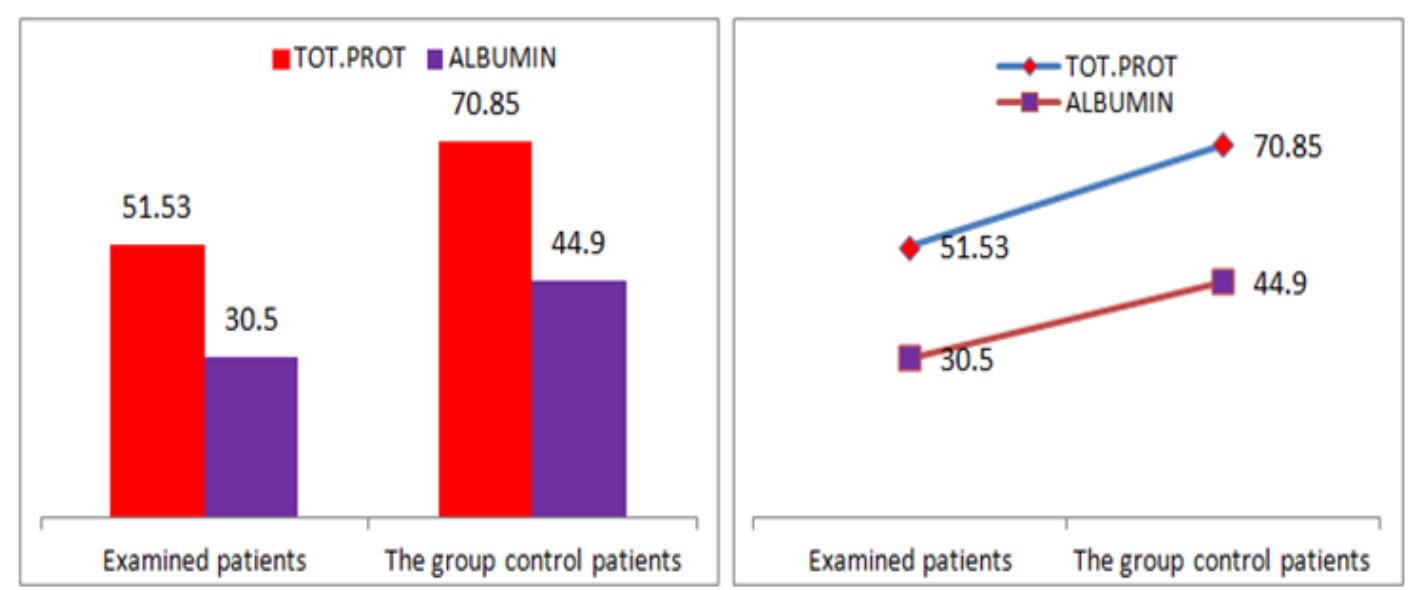

Figure 8: Graphic representations of total protein counts in albumin in patients with diabetic nephropathy and in control group patients.
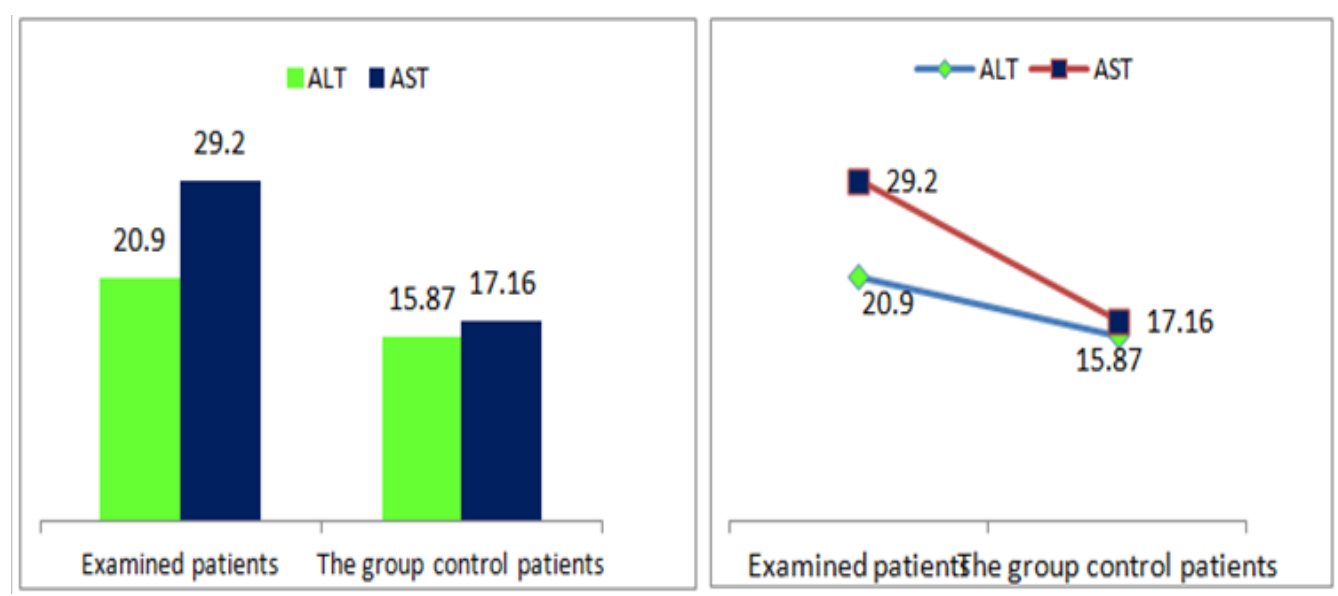

Figure 9: Graphic presentations of transaminase values in patients with diabetic nephropathy and patients in the control group. 
Result 1: Paired T-Test and CI: 1 Initial Proteinuria gr/1, 2 Initial Proteinuria ; gr/1 .

\begin{tabular}{|c|c|c|c|c|c|}
\hline S.No & & N & Mean & St Dev & SE Mean \\
\hline 1 & Initial Proteinuria & 80 & 159.73 & 36.94 & 4.13 \\
\hline 2 & Initial Proteinuria & 80 & 2.60 & 1.14 & 0.13 \\
\hline & Difference & 80 & 157.13 & 36.90 & 4.13 \\
\hline
\end{tabular}

95\% CI for mean difference: $(148.92,165.34)$

$\mathrm{T}$-Test of mean difference $=0(\mathrm{vs} \neq 0): \mathrm{T}-$ Value $=38.09, \mathrm{P}-$ Value $=0.000$

Paired T-Test and CI: 1 Initial Proteinuria gr/1, 2 Initial Proteinuria; gr/1

Paired T for 1 Initial Proteinuria gr/1 - 2 Initial Proteinuria; grl

Result 2: Paired T-Test and CI: 1 Proteinuria after 3 months, gr/1, 2 Proteinuria after 3 months; g/1.

\begin{tabular}{|c|c|c|c|c|c|}
\hline S.No & & N & Mean & St Dev & SE Mean \\
\hline 1 & Proteinuria after 3 months & 80 & 161.57 & 31.31 & 3.50 \\
\hline 2 & Proteinuria after 3 months & 80 & 1.48 & 0.60 & 0.07 \\
\hline & Difference & 80 & 160.09 & 31.28 & 3.50 \\
\hline
\end{tabular}

95\% CI for mean difference: $(153.13,167.05)$

T-Test of mean difference $=0(\mathrm{vs} \neq 0)$ : T-Value $=45.78, \mathrm{P}$-Value $=0.000$

Paired T-Test and CI: 1 Proteinuria after 3 months, gr/1, 2 Proteinuria after 3 months; g/1

Paired T for 1 Proteinuria after 3 months, gr/ 1 - 2 Proteinuria after 3 months; g_1

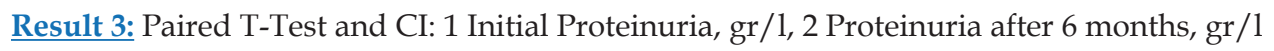

\begin{tabular}{|c|c|c|c|c|}
\hline S.No & & N & Mean & St Dev \\
\hline 1 & Initial Proteinuria & 79 & 161.94 & 30.81 \\
\hline 2 & Proteinuria after 6 months & 79 & 1.05 & 1.66 \\
\hline & Difference & 79 & 160.89 & 30.84 \\
\hline
\end{tabular}

95\% CI for mean difference: $(153.98,167.80)$

$\mathrm{T}$-Test of mean difference $=0(\mathrm{vs} \neq 0): \mathrm{T}$-Value $=46.37 \mathrm{P}$-Value $=0.000$

Paired T-Test and CI: 1 Initial Proteinuria, gr/1, 2 Proteinuria after 6 months, gr/1

Paired T for 1 Initial Proteinuria, gr/1 - 2 Proteinuria after 6 months, gr/1

Result 4: Paired T-Test and CI: 1 WBC, 2 WBC.

\begin{tabular}{|c|c|c|c|c|c|}
\hline S.No & & N & Mean & St Dev & SE Mean \\
\hline 1 & WBC & 80 & 7.466 & 1.406 & 0.157 \\
\hline 2 & WBC & 80 & 8.692 & 1.388 & 0.379 \\
\hline & Difference & 80 & -1.227 & 3.495 & 0.391 \\
\hline
\end{tabular}

95\% CI for mean difference: $(-2.004,-0.449)$

$\mathrm{T}$-Test of mean difference $=0(\mathrm{vs} \neq 0): \mathrm{T}-$ Value $=-3.14, \mathrm{P}$-Value $=0.002$

Paired T-Test and CI: 1 WBC, 2 WBC

Paired T for 1 WBC - 2 WBC

Result 5: Paired T-Test and CI: 1 RBC, 2 RBC.

\begin{tabular}{|c|c|c|c|c|c|}
\hline S.No & & N & Mean & St Dev & SE Mean \\
\hline 1 & RBC & 79 & 4.249 & 3.269 & 0.368 \\
\hline 2 & RBC & 79 & 3.432 & 0.880 & 0.099 \\
\hline & Difference & 79 & 0.817 & 3.346 & 0.376 \\
\hline
\end{tabular}

95\% CI for mean difference: $(0.067,1.566)$ 
$\mathrm{T}$-Test of mean difference $=0(\mathrm{vs} \neq 0): \mathrm{T}-$ Value $=2.17, \mathrm{P}$-Value $=0.033$

Paired T-Test and CI: 1 RBC, 2 RBC

Paired T for 1 RBC - 2 RBC

Result 6: Paired T-Test and CI: 1 HGB, 2 HGB

\begin{tabular}{|c|c|c|c|c|c|}
\hline S.No & & N & Mean & St Dev & SE Mean \\
\hline 1 & HGB & 79 & 15.47 & 18.25 & 2.05 \\
\hline 2 & HGB & 79 & 15.45 & 12.40 & 1.40 \\
\hline & Difference & 79 & 4.02 & 22.32 & 2.51 \\
\hline
\end{tabular}

95\% CI for mean difference: $(-0.98,9.02)$

$\mathrm{T}$-Test of mean difference $=0($ vs $\neq 0): \mathrm{T}-$ Value $=1.60, \mathrm{P}$-Value $=0.113$

Paired T-Test and CI: 1 HGB, 2 HGB

Paired T for 1 HGB - 2 HGB

Result 7: Paired T-Test and CI: 1 HCT, 2 HCT.

\begin{tabular}{|c|c|c|c|c|c|}
\hline S.No & & N & Mean & St Dev & SE Mean \\
\hline 1 & HCT & 79 & 35.190 & 4.126 & 0.464 \\
\hline 2 & HCT & 79 & 29.192 & 7.439 & 0.837 \\
\hline & Difference & 79 & 6.00 & 8.91 & 1.00 \\
\hline
\end{tabular}

95\% CI for mean difference: $(4.00,7.99)$

$\mathrm{T}$-Test of mean difference $=0(\mathrm{vs} \neq 0): \mathrm{T}-$ Value $=5.98, \mathrm{P}-$ Value $=0.000$

Paired T-Test and CI: 1 HCT, 2 HCT

Paired T for 1 HCT - 2 HCT

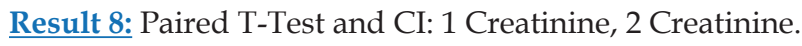

\begin{tabular}{|c|c|c|c|c|c|}
\hline S.No & & N & Mean & St Dev & SE Mean \\
\hline 1 & Creatinine & 80 & 74.9 & 16.0 & 3.8 \\
\hline 2 & Creatinine & 80 & 505.3 & 331.9 & 37.1 \\
\hline & Difference & 80 & -430.5 & 335.2 & 37.5 \\
\hline
\end{tabular}

95\% CI for mean difference: (-505.0, -355.9)

$\mathrm{T}$-Test of mean difference $=0(\mathrm{vs} \neq 0): \mathrm{T}-$ Value $=-11.49, \mathrm{P}$-Value $=0.000$

Paired T-Test and CI: 1 Creatinine, 2 Creatinine

Paired T for 1 Creatinine - 2 Creatinine

Result 9: Paired T-Test and CI: 1. Total Proteins, Total Proteins.

\begin{tabular}{|c|c|c|c|c|c|}
\hline S.No & & N & Mean & St Dev & SE Mean \\
\hline 1 & Total P & 80 & 65.831 & 5.336 & 0.597 \\
\hline 2 & Total P & 80 & 62.201 & 8.549 & 0.956 \\
\hline & Difference & 80 & 3.63 & 10.29 & 1.15 \\
\hline
\end{tabular}

95\% CI for mean difference: $(1.34,5.92)$

$\mathrm{T}$-Test of mean difference $=0(\mathrm{vs} \neq 0): \mathrm{T}$-Value $=3.15, \mathrm{P}$-Value $=0.002$

Paired T-Test and CI: 1 Total Proteins, Total Proteins

Paired T for 1 Total P-Total P

Result 10: Paired T-Test and CI: 1 Uric Acid. 2 Uric Acid.

\begin{tabular}{|c|c|c|c|c|c|}
\hline S.No & & N & Mean & St Dev & SE Mean \\
\hline 1 & Uric Acid & 79 & 283.2 & 85.2 & 9.6 \\
\hline
\end{tabular}




\begin{tabular}{|l|c|c|c|c|c|}
\hline 2 & Uric Acid & 79 & 390.6 & 143.9 & 16.2 \\
\hline & Difference & 79 & -107.5 & 151.5 & 17.0 \\
\hline
\end{tabular}

95\% CI for mean difference: $(-141.4,-73.6)$

$\mathrm{T}$-Test of mean difference $=0($ vs $\neq 0): \mathrm{T}$-Value $=-6.3, \mathrm{P}$-Value $=0.000$

Paired T-Test and CI: 1 Uric Acid, 2 Uric Acid

Paired T for 1 Uric Acid - 2 Uric Acid

Result 11: Paired T-Test and CI: 1 ALT, 2 ALT.

\begin{tabular}{|c|c|c|c|c|c|}
\hline S.No & & N & Mean & St Dev & SE Mean \\
\hline 1 & ALT & 80 & 26.24 & 44.28 & 4.95 \\
\hline 2 & ALT & 80 & 21.63 & 14.72 & 1.65 \\
\hline & Difference & 80 & 4.61 & 46.92 & 5.25 \\
\hline
\end{tabular}

95\% CI for mean difference: $(-5.83,15.05)$

$\mathrm{T}$-Test of mean difference $=0(\mathrm{vs} \neq 0)$ : T-Value $=0.88, \mathrm{P}-$ Value $=0.382$

Paired T-Test and CI: 1 ALT, 2 ALT

Paired T for 1 ALT - 2 ALT

Result 12: Paired T-Test and CI: 1 AST, 2 AST.

\begin{tabular}{|c|c|c|c|c|c|}
\hline S.No & & N & Mean & St Dev & SE Mean \\
\hline 1 & AST & 80 & 38.0 & 181.3 & 20.3 \\
\hline 2 & AST & 80 & 23.6 & 18.4 & 2.1 \\
\hline & Difference & 80 & 14.4 & 182.7 & 20.4 \\
\hline
\end{tabular}

95\% CI for mean difference: $(-26.3,55.1)$

$\mathrm{T}$-Test of mean difference $=0(\mathrm{vs} \neq 0): \mathrm{T}-$ Value $=0.71, \mathrm{P}-$ Value $=0.483$

Paired T-Test and CI: 1 AST, 2 AST

Paired T for 1 AST - 2 AST

Result 13: Paired T-Test and CI: 1 Albumin, 2 Albumin.

\begin{tabular}{|c|c|c|c|c|c|}
\hline S.No & & N & Mean & St Dev & SE Mean \\
\hline 1 & Albumin & 80 & 34.869 & 5.410 & 0.605 \\
\hline 2 & Albumin & 80 & 35.319 & 6.522 & 0.729 \\
\hline & Difference & 80 & -0.450 & 7.718 & 0.863 \\
\hline
\end{tabular}

95\% CI for mean difference: $(-2.168,1.268)$

T-Test of mean difference $=0(v s \neq 0):$-Value $=-0.52, \mathrm{P}$-Value $=0.603$

Paired T-Test and CI: 1 Albumin, 2 Albumin

Paired T for 1 Albumin - 2 Albumin

Result 14: Paired T-Test and CI: 1 Cholesterol, 2 Cholesterol.

\begin{tabular}{|c|c|c|c|c|c|}
\hline S.No & & N & Mean & St Dev & SE Mean \\
\hline 1 & Cholesterol & 78 & 4.391 & 0.884 & 0.100 \\
\hline 2 & Cholesterol & 78 & 4.743 & 1.374 & 0.156 \\
\hline & Difference & 78 & -0.352 & 1.644 & 0.186 \\
\hline
\end{tabular}

95\% CI for mean difference: $(-0.722,0.019)$

$\mathrm{T}$-Test of mean difference $=0($ vs $\neq 0):$ T-Value $=-1.89, \mathrm{P}$-Value $=0.063$

Paired T-Test and CI: 1Cholesterol, 2Cholesterol

T for 1 Cholesterol-2 Cholesterol 
Result 15: Paired T-Test and CI: 1 Triglycerides 2 Triglycerides.

\begin{tabular}{|c|c|c|c|c|c|}
\hline S.No & & N & Mean & St Dev & SE Mean \\
\hline 1 & Triglycerides & 80 & 1.567 & 0.650 & 0.073 \\
\hline 2 & Triglycerides & 80 & 1.828 & 1.080 & 0.121 \\
\hline & Difference & 80 & -0.261 & 1.230 & 0.138 \\
\hline
\end{tabular}

95\% CI for mean difference: $(-0.534,0.013)$

$\mathrm{T}$-Test of mean difference $=0(\mathrm{vs} \neq 0)$ : T-Value $=-1.90, \mathrm{P}$-Value $=0.062$

Paired T-Test and CI: 1 Triglycerides 2 Triglycerides

Paired T for 1 Triglycerides - 2 Triglycerides

\section{Conclusion}

All 162 patients with type 2 diabetes and renal insufficiency after treatment with Pentoxiphyllin $400 \mathrm{mg}$, three times a day have decreased proteinuria or reduced protein loss in the urine in a significant way. Although all these patients were treated with ACE or ARB, the possibility that the main factor of protein reduction was ACE or ARB, even in the second quarter, which means after the 6-month study we see that there is much more significant decrease of protein loss through urine compared with treatment initiation values, also with the value of the first quarter of treatment it is proved that the effect of Pentoxypilline in decreasing the loss of protein in the urine, it is confirmed by the healthy control group that expose the study.

Comparison of T-Test lab tests among patients treated with Pentoxiphylline $400 \mathrm{mg}$ and patients with placebo statistical difference had leukocytes, erythrocytes, Hematocrit, Creatinine, total protein and uric acid, while the values of laboratory analyzes that did not differ (ALT, P-Value $=0.382$ ), AST values (AST, P-Value $=0.483$ ), Albumin values, P- Value $=0.603$ ), Cholesterol Values (Cholesterol, P-Value $=0.063$ ) and triglyceride values (Triglycerides, $\mathrm{P}$-Value $=0.062$ ). In all cases we see that the values of $\mathrm{P}$ are greater than the allowed values 0.05 . Based on the results of the survey, we conclude that Pentoxiphylline $400 \mathrm{mg}$, three times a day therapy has a good effect on decreasing protinunuria and preventing kidney failure.

The applied dose is not toxic and has no kidney effects. The results of our study are sufficiently consistent with the results of many authors in their papers published in scientific journals such as ERA-EDTA or JAS, Nephrology etc.

\section{References}

1. Park CW (2014) Diabetic kidney disease: from epidemiology to clinical perspectives. Diabetes Metab J 38(4): 252-260.

2. Mima A, Qi W, King GL (2012) Implications of treatment that target protective mechanisms against diabetic nephropathy. Semin Nephrol 32(5): 471-478.

3. American Diabetes, Association (2014) Standards of medical care in diabetes--2014. Diabetes Care 37(Supply 1): S14-S80.
4. Nobakht N, Kamgar M, Rastogi A, Schrier RW (2011) Limitations of angiotensin inhibition. Nat Rev Nephrol 7(6): 356-359.

5. Windmeier C, Gressner AM (1997) Pharmacological aspects of pentoxifylline with emphasis on its inhibitory actions on hepatic fibrogenesis. Gen Pharmacol 29(1): 181-196.

6. Rodriguez-Moran M, Guerrero-Romero F (2008) Efficacy of pentoxifylline in the management of microalbuminuria in patients with diabetes. Curr Diabetes Rev 4(1): 55-62.

7. Navarro JF, Mora C, Muros M, Garcia J (2005) Additive antiproteinuric effect of pentoxifylline in patients with type 2 diabetes under angiotensin II receptor blockade: a short-term, randomized, controlled trial. J Am Soc Nephrol 16(7): 2119-2126.

8. Navarro JF, Mora C, Muros M, Maca M, Garca J (2003) Effects of pentoxifylline administration on urinary $\mathrm{N}$-acetyl-beta-glucosaminidase excretion in type 2 diabetic patients: a short-term, prospective, randomized study. Am J Kidney Dis 42(2): 264-270.

9. Ward A, Clissold SP (1987) Pentoxifylline. A review of its pharmacodynamic and pharmacokinetic properties, and its therapeutic efficacy. Drugs 34(1): 50-97.

10. Diskin CJ, Stokes TJ, Dansby LM, Radcliff L, Carter TB (2007) Will the addition of pentoxifylline reduce proteinuria in patients with diabetic glomerulosclerosis refractory to maximal doses of both an angiotensinconverting enzyme inhibitor and an angiotensin receptor blocker? J Nephrol 20(4): 410-416.

11. Goicoechea M, Garcia De Vinuesa S, Quiroga B, Verdalles U, Barraca D, et al. (2012) Effects of pentoxifylline on inflammatory parameters in chronic kidney disease patients: a randomized trial. J Nephrol 25(6): 969-975.

12. McCormick BB, Sydor A, Akbari A, Fergusson D, Doucette S, et al. (2008) The effect of pentoxifylline on proteinuria in diabetic kidney disease: a meta-analysis. Am J Kidney Dis 52(3): 454-463.

13. Shan D, Wu HM, Yuan QY, Li J, Zhou RL, et al. (2012) Pentoxifylline for diabetic kidney disease. Cochrane Database Syst Rev 2: CD006800.

14. Perkins RM, Aboudara MC, Uy AL, Olson SW, Cushner HM, et al. (2009) Effect of pentoxifylline on GFR decline in CKD: a pilot, double-blind, randomized, placebo-controlled trial. Am J Kidney Dis 53(4): 606-616.

15. Blagosklonnaia Ia V, Mamedov R, Kozlov VV, Emanuel VL, Kudriashova MI (1982) Effect of trental on indices kidney function in diabetes mellitus. Probl Endokrinol (Mosk) 28(3): 3-8.

16. Navarro-Gonzalez JF, Mora-Fernandez C (2008) The role of inflammatory cytokines in diabetic nephropathy. J Am Soc Nephrol 19(3): 433-442. 
CC (P) This work is licensed under Creative

Submission Link: https://biomedres.us/submit-manuscript.php

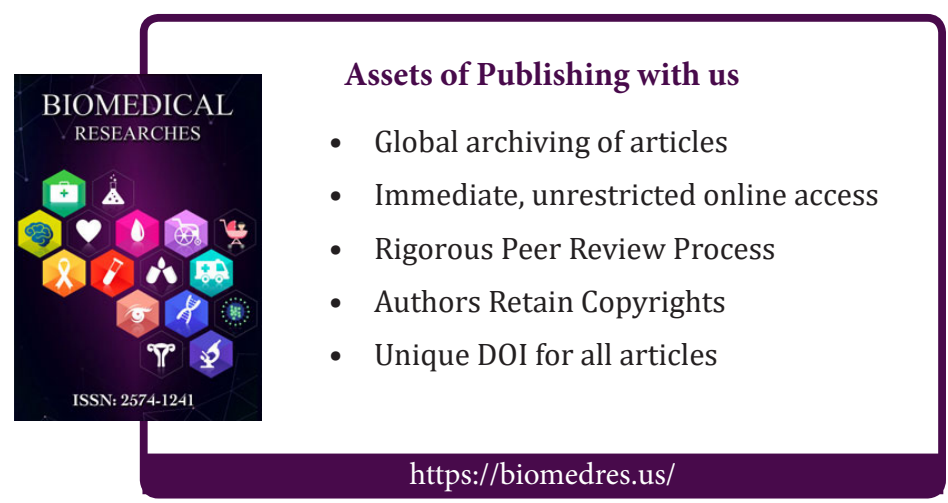

